\title{
Article \\ Transport and Access to Inclusive Education in Mashonaland West Province, Zimbabwe
}

\author{
Maria Kett * and Marcella Deluca \\ Leonard Cheshire Disability and Inclusive Development Centre, University College London, London, WC1E 6BT, UK; \\ E-Mails: m.kett@ucl.ac.uk (M.K.), marcella.deluca@ucl.ac.uk (M.D.) \\ * Corresponding author
}

Submitted: 4 November 2015 | Accepted: 22 February 2016 | Published: 7 June 2016

\begin{abstract}
Lack of accessible transportation is considered a major barrier to education for children with disabilities - children already far less likely to attend school. While millions of children face challenges with getting to school, including long distances, poor roads, lack of transport and safety issues, these can be compounded for children with disabilities. Yet there is little data from low and middle-income countries on the nature and extent of this exclusion, or on attempted solutions. This paper explores some practical options for improving transport as part of providing inclusive education for children with disabilities in low income countries, as well applying concepts of transport-related social exclusion in such contexts. The paper reviews a project designed to improve sustainable transportation to school for children with disabilities in four districts in Mashonaland West Province, Zimbabwe. The most common solution was three wheel motorbikes (tricycles) with trailers. Whilst not been unproblematic, teachers, parents and the wider communities overwhelmingly agree that they have supported children with disabilities to attend school. Obviously tricycles are not the only component needed for an inclusive education system, but they are a start. The paper also highlights some crucial gaps in current approaches, key among which is the fact the most government departments work in silos. Whilst inclusive education is strongly supported by the Zimbabwean Government, there is a lack of joined up thinking between transport and education ministries. Without stronger collaboration across ministries children with disabilities will continue to experience avoidable barriers and transport-related social exclusion.
\end{abstract}

\section{Keywords}

accessibility; children with disabilities; inclusive education; participation; social exclusion; tricycles; transport solutions; Zimbabwe

\section{Issue}

This article is part of the issue "Transport Policy and Social Inclusion", edited by Miriam Ricci, Graham Parkhurst and Juliet Jain (University of the West of England, UK).

(C) 2016 by the authors; licensee Cogitatio (Lisbon, Portugal). This article is licensed under a Creative Commons Attribution 4.0 International License (CC BY).

\section{Introduction: Reconceptualising What Access Means in the Zimbabwe Context}

To date there have been limited studies published on the impact of transport-related social exclusion on children with disabilities, nor specifically on how the lack of affordable, accessible transport may affect their access to education. This paper is an attempt to redress this gap, and will describe some of the impacts of integrating transport solutions into an inclusive education project, as well as community understanding of the challenges and opportunities that such an undertaking represents.

At a basic level, access to and from education is a fundamental right of a child, and when they are unable to exercise this right, they can be socially excluded from society both immediately and in the future. However, how we measure the ability of people to get to and from school is a more complex problem. At a mac- 
ro-level, since the publication of the seminal report from the Social Exclusion Unit in the UK (Social Exclusion Unit, 2003), there has been a shift in focus on what social exclusion means in different contexts and for different groups. It is now well-established that social exclusion is a multi-faceted, relational problem that is exclusion is comparable to the social norms of a community or society; and one which changes over time; (Lucas, 2012). Causal factors of social exclusion associated to transport can be seen at three levels: the level of the individual, the community/local area and the country/global level (Lucas, 2012).

There is an accepted link between physical inaccessibility and transport-related social exclusion (e.g. Bannister \& Hall, 1981), as well as multiple policies to enable accessibility for persons with disabilities. However, the majority of these have been in higher income countries; moreover, merely having a policy in place has not automatically improved transport-related social exclusion (Lucas, 2012). Accessibility is critical to a person's basic human rights and is enshrined in Article 9 of the UN Convention on the Rights of Persons with Disabilities (UN, 2007). Under Article 9, a state must give equal access to public buildings and transportation to people with disabilities; something which is achieved via a number of different modes in higher income countries, ranging from adaptations such as low-floor buses to taxi cards which allow a person to travel free of charge for a specified number of journeys. However, in lower income countries such adaptations and policies are in many instances cost-prohibitive and therefore new methods must be found to help ensure people with disabilities obtain equal access. One such method which has been applied in other domains is that of participatory design (Stevens et al., 2014). This approach allows citizens to have a voice in both the design of solutions as well as in the collection of data.

Given the wide ranging exclusion of persons with disabilities in lower income countries (e.g. Groce, Kett, Lang, \& Trani, 2012), in this paper we explore if transport-related exclusion theories can be usefully applied as a framework to better understand the mechanisms of transport-related social exclusion of adults and children with disabilities? Or, put differently, can the debates be moved beyond the policy level to suggest ways to reduce transport-related social exclusion in lower income countries, and is a participatory approach useful to initiate discussion around an accessible transport system for children in Zimbabwe? This article explores practical community-led options for improving transport as part of a programme providing inclusive education for children with disabilities in a low income country context. Such an approach chimes with a more rights-based approach to disability inclusion, and focuses less on what is and is not available, and more on what the consequences of this are in terms of access to opportunities, including education and employment (Lucas, 2012, p. 106).

This research, undertaken by the Leonard Cheshire Disability and Inclusive Development Centre at UCL in collaboration with the Leonard Cheshire Disability Zimbabwe Trust, set out to understand three main issues related to transportation for children with disabilities to and from school:

1. The extent to which teachers, parents and caregivers understand transport (or lack of transport) to be a barrier to education for children with disabilities;

2. The 'solutions' communities propose to overcome the barriers;

3. Whether the solutions proposed and piloted in this project appear to be sustainable and effective over time.

While of the components of the overall programme focused on ascertaining the effectiveness of the 'transport solutions', it should be stated from the outset that this was not an evaluation of the methods, but rather an attempt to better understand the transportrelated barriers and exclusions that children with disabilities face, and what, if any, impact the communityled solutions had. We should also underscore the fact that we cannot make any direct inferences about the successes of the methods chosen in these communities for broader implementation-this was not a randomised trial, and there were numerous other counterfactuals and causal links. However, what the research can do is to allow us to highlight some specific findings regarding the links between access to school, transport, and children with disabilities in lower income countries - something missing from the literature to date; as well as understand how communities adapt policies and practices to make them work in the local context.

In order to do this, the paper will first outline the current debates in transport-related social exclusion and the extent to which these have been applied to low income country contexts. It will then move on to discuss the inclusive education project in more detail, specifically the research around accessible transport solutions. Finally, we present the findings of this research before closing with a discussion around the implications of these findings more broadly.

\section{Transport-Related Exclusion}

The majority of the studies on access to transportation to school and other facilities for persons with disabilities or other disadvantaged groups have been undertaken in middle and high income countries (see for example, Currie et al., 2010; Schwanen et al., 2015; Whitzman, James, \& Poweseu, 2013). Within much of this work, researchers have suggested direct causal links between transport and social exclusion, particu- 
larly through an expansion of empirical research (Schwanen et al., 2015, p. 1). To some extent this paper builds on this tradition and argues that this in itself has value in drawing attention to the impact of such causal links on the lives of adults and children with disabilities in low income countries.

Zimbabwe faces all of the commonly highlighted challenges in the literature, which can be summarized as follows:

i) Physical exclusion: whereby physical barriers, such as vehicle design, lack of disabled facilities or lack of timetable information, inhibit the accessibility of transport services;

ii) Geographical exclusion: where a person lives can prevent them from accessing transport services, such as in rural areas or on peripheral urban estates;

iii) Exclusion from facilities: the distance of key facilities such as schools, shops, healthcare or leisure services from where a person lives prevents their access;

iv) Economic exclusion: the high monetary costs of travel can prevent or limit access to facilities or employment and thus impact on incomes;

v) Time-based exclusion: other demands on time, such as combined work, household and childcare duties, reduces the time available for travel (often referred to as time-poverty in the literature);

vi) Fear-based exclusion: where fears for personal safety preclude the use of public spaces and/or transport services;

vii) Space exclusion: where security or space management prevent certain groups access to public spaces, e.g. gated communities or first class waiting rooms at stations.

(Adapted from Church et al., 2003, pp. 198-200).

Critics argue that while this approach is helpful in identifying the challenges, it fails to identify where barriers exist, in what priority these issues should be addressed, and how policy attention should be focused (Lucas, 2012). In order to address these gaps, other approaches have been suggested; for example, Grieco, 2006 (cited in Lucas, 2011) proposed adding the following to the list above:

(i) Place-based measures, including opportunities and services within the immediate area in which a person lives;

(ii) Social-category based measures, such as social stratification within a community to identify social need;

(iii) Person-based measures, such as the individual public transport user's profile of journey needs.
Whatever the measures used, they should be seen as dynamic, and existing against a backdrop of ever changing needs and mobility. Moreover, most of the work done identifies multifaceted challenges beyond the control of the transport sector alone and thus necessitate integration across two or more departments and ministries.

However, most development policy focus has not been on these challenges, but on large scale transport infrastructure projects as a social development tool, rather than on the travel needs of local communities, despite the fact that a focus on the travel needs of the local community may result in less expensive, more context-specific and-perhaps-more inclusive solutions (Lucas, 2012).

For example, the majority of studies undertaken in rural South Africa identify an almost complete absence of public transport services, resulting in an overreliance on walking, which in turn gives rise to a range of inequalities particularly affecting women's participation in paid employment and formal economic opportunities. These inequalities may also result in low uptake of healthcare and educational opportunities (Lucas, 2011, p. 1321). In both urban and rural areas in many lower income countries-including South Africa, Kenya and Zimbabwe-often the biggest challenges are not the lack of transport per se-the ubiquitous Kombi or Matatu minivans, taxis and motorbikes cover extensive networks in many countries-but rather that these options may be unaffordable, unsafe, unreliable and unsuitable for the often long journeys that must be undertaken to access work, healthcare facilities and other key destinations. However, while there has been some work around transport exclusion and healthcare (see for example Banda-Chalwe, Nitz, \& de Jonge, 2012; Van Rooy et al., 2012), to date none have focused specifically on access to education for children with disabilities.

Therefore despite a range of approaches to reduce transport-related social exclusion, as well as a growing body of academic literature critiquing such approaches, there are still people who are out of reach of most policies and practices, and it is to these people that developing participatory community-led approaches-and assessments - may offer a solution.

\subsection{Transport Policy in Zimbabwe}

Most Zimbabweans face many of the same challenges as transport structures in low income countries around the world, including South Africa: affordability, availability, (lack of) infrastructure, (lack of) policy and planning and regulation (see for example, Lucas, 2011; Walters, 2008), and an (over) reliance on low capacity vehicles (e.g. minibuses or Kombis, as they are known in Zimbabwe). It is also a hugely unsafe sectoraccording to national data, around $20 \%$ of disabilities in the country are related to road traffic incidents (Minis- 
try of Health and Child Welfare, 2009).

Zimbabwe is attempting to respond to these challenges by changes in policy and practice. For example, the Government of Zimbabwe (GoZ) recently launched its National Transport Policy (Chideme, 2013) one aim of which was to reduce the dependency on low capacity vehicles (Kombis) by replacing commuter omnibuses with high-volume buses operated by a limited number of private players between 2014 and 2016. In part this was a political decision as Kombi drivers can be a considerable voting bloc, but there are other potential complications too, not least cost. Therefore while on the one hand, it is an opportunity to improve and /or introduce accessible transport options; on the other, it will most likely simply reduce the number of transport options available to many passengers (see also African Development Fund, 2013).

Such changes in policy have direct implications for persons with disabilities in general. For example, according to the National Transport Master Plan (African Development Fund, 2013), which is linked to the National Transport Policy and Medium Term Development (MTD) plan, and which has a specific focus on persons with disabilities, Rural District and Urban Councils and the District Development Fund will continue to be responsible for urban and rural roads respectively; while the MTD emphasises the role of communities in road maintenance. Though beyond talking about community programmes it does not elaborate on how this will be undertaken. Unfortunately however, the Transport Master Plan has no clearly stated comprehensive transport/social inclusion links.

Taken together, the policy environment in Zimbabwe may be tantalising close to an inclusive policy, but it is as yet unclear how it will be implemented; moreover, it is also unclear what alternative transport options will be provided. Furthermore, nowhere is the issue of access to transportation by children with disabilities specifically considered, despite the GoZ commitments elsewhere, including to the UN Convention on the Rights of Persons with Disabilities.

\section{Inclusive Education, Transport and Community Based Solutions}

Between April 2013 and December 2015, the Leonard Cheshire Disability Zimbabwe Trust implemented a UK Department of International Development (DFID)funded project to promote inclusive education in Mashonaland West Province (MWP), Zimbabwe. ${ }^{1}$ Based on local awareness of gaps in access, a component of the project focused on developing innovative, community-led transport solutions to enable children to access

${ }^{1}$ Global Poverty Action Fund project 'Promoting the Provision of Inclusive Primary Education for Children with Disabilities in Mashonaland West Province, Zimbabwe'. school in light of the general lack of attention to the accessible transportation needs noted above. To address some of these challenges, a pilot project was developed in conjunction with the inclusive education programme to facilitate access to school. Sustainable, accessible transport solutions were developed by the project team in collaboration with the communities themselves through a series of meetings and focus groups, taking into account the local context and limited project budget. From the outset, it was intended that whatever the solutions, they would be fully owned and maintained by the communities themselves. Based on the children's needs, the local terrain and weather-in particular heavy rains, and local availability, two main solutions were decided upon-scotch carts ${ }^{2}$ pulled by donkeys, and trailers pulled by tricycles, both produced locally and at low cost. Communities agreed these would be cost-effective, easy to maintain, suitable for the poor road network and efficient in terms of the number of children that could be transported to school in a single journey. On average, the trailers can transport eight children at any one time. The overwhelming majority of communities opted to purchase tricycles with trailers, and over the course of the threeyear project, 20 tricycles with trailers were purchased for 20 eligible schools in the four districts. ${ }^{3}$

The vehicles were provided through a project grant, with the drivers-often parents or teachers from the schools-selected and paid a small stipend by the School Development Committees (SDC). SDCs are elected bodies, composed of parents and other community members, who, along with teachers, have a managerial oversight role of the school. They also agree levies for fees and other additional resources. The SDCs can be powerful advocates or opponents of innovations such as the tricycle transportation scheme, depending on perspective.

With regards to sustainability, during the course of the project some parents and SDCs set up income generating projects such as keeping chickens or growing vegetable at the schools to raise funds to pay the drivers. One group even talked about developing a community-based transport co-operative, which would require funding through community projects, though this had not taken place at the time of writing.

\section{Research Methodology}

We employed several different approaches in order to address the following research questions:

\section{The extent to which teachers, parents and}

\footnotetext{
2 Usually for agricultural use, these are designed to hold heavy loads and be pulled by an ox or donkey. They are also usually made locally in Zimbabwe.

${ }^{3} \mathrm{~A}$ total of 30 model schools were included in the project.
} 
caregivers understand transport (or lack of transport) to be a barrier to education for children with disabilities;

2. The 'solutions' communities propose to overcome the barriers;

3. Whether the solutions proposed and piloted in this project appear to be sustainable and effective over time.

These approaches were a structured comparative survey in the four selected districts in MWP (Hurungwe, Kariba, Mhondoro Ngezi, and Sanyati), which aimed to gauge the knowledge, attitudes and practices (KAP) of head teachers, teachers and parents/caregivers about the education of children with disabilities. A preintervention survey was administered in the field by a trained survey team to a total of 441 head teachers, teachers and parents/caregivers in July 2013 (Deluca, Tramontano, \& Kett, 2014a\&2014b), and a postintervention survey of 408 informants was undertaken in June 2015 in order to measure changes over the lifetime of the intervention. The survey is currently being analysed at time of writing (Deluca, Pinilla-Roncancio, \& Kett, 2016, forthcoming).

The survey included questions around a range of barriers to education for children with disabilities. Whilst the majority of the barriers identified were at the school level, and included the school environment, teacher attitudes, inaccessible classrooms and toilets, etc., there were also a number of external factors which head teachers, teachers and parents/caregivers identified as barriers. Here transportation was a key concern.

In order to get an understanding of what the communities themselves thought, particularly teachers and parents, about issues around access to schools and sustainable community transport solutions we undertook a series of group discussions. In total eight workshops were undertaken (two in each intervention area). The first round of research was undertaken in May 2014, when four workshops were conducted (one in each of the project areas). The aim of these workshops was to bring together a range of stakeholders, including parents and children with disabilities, other community members, drivers (of taxis and buses where possible) to discuss current local transport options for adults and children with disabilities, as well as to try and discuss possible 'solutions' to transport challenges. A total of 55 persons participated in these groups. ${ }^{4}$ At the initial

${ }^{4}$ Broken down as follows: Sanyati: seven teachers (one per school); six parents (including parents of children with disabilities); two taxi drivers; and two persons with disabilities. Mhondoro-Ngezi: seven teachers (one per school, including one classroom assistant, six parents (including parents of children with disabilities); four taxi drivers; and two persons with disabilities. Kariba: Four school development committee (SDC) workshop, participants were placed into groups based on where they lived to ensure that the discussion ranged around a broad set of perspectives from the same locations/routes etc. Each group was asked to draw one map to represent transport currently available, and the challenges that using these options do or may present for persons with disabilities in particular. They were then asked to draw a second map to suggest possible solutions-or what they would like to see as options. They then presented these annotated maps back to the group for discussion.

These were followed up almost a year later (April 2015), when we undertook a second round of workshops in the same communities. It was not always possible to identify the same participants as before due to challenges in location, changes in address etc. However, representatives of the same groups-parents (of children with disabilities), teachers, head teachers and drivers (of the tricycles) were again included in the workshops. The aim of these was to explore a series of questions around the transport 'solutions' provided in each of the four districts. Participants were asked to join their respective school groups and discuss a series of questions about the transport solutions implemented in their schools. These focused on effectiveness, organisation, usage, cost, maintenance, ownership and sustainability.

Below is a summary of the findings from the survey and workshops. The first section highlights the outcomes from the initial round or workshops discussing barriers, potential solutions and challenges-and it should be noted that at this point, communities and schools had not yet been given the transport grants. The second section discusses the results from workshops held after the transport solutions had been implemented.

\section{Findings}

Results from both the KAP survey highlight a number of transport-related barriers. For example, in the preintervention survey, head teachers, teachers and parents/caregivers overwhelmingly agreed with the statement that 'schools are a long distance from home $^{5}$ : $87.9 \%$ of head teachers $(N=66), 86.2 \%$ of teachers $(\mathrm{N}=180)$, and $67.0 \%$ of caregivers $(\mathrm{N}=179)$. Linked to the question of distance was a question about means of transport to school. Again, all three groups (head teachers, teachers and parents/caregivers)

members; three parents of children with disabilities; one taxi driver and one person with disabilities. Hurungwe: three SDC members; two classroom assistants; five parents of children with disabilities; two taxi drivers and one person with disabilities.

${ }^{5}$ No distance was specified in the survey, in part to facilitate future discussions on what a 'long distance' means across communities. 
overwhelmingly agreed that there was no means of transport to school: $81.9 \%$ of head teachers $(\mathrm{N}=66)$, $80.7 \%$ of teachers $(\mathrm{N}=181), 70.2 \%$ of caregivers ( $N=178$ ) (Deluca et al., 2014a). However, it is important to note that some of the children with disabilities may not be attending their nearest school; rather they may be attending the nearest schools included in the IE project. Also, when questioned about distances, parents had varied opinions about the distances between homes and school, which apparently could be up to $3 \mathrm{~km}$ each way. Of course, distance perception is highly subjective, and depends on what adults and children consider to be a long distance; as well as the context, degree of difficulty, and what transport methods are available and used, and by whom. Nevertheless, it also underscores how a relatively short distance may pose many challenges in school attendance for some children.

In practice, most children have to travel by foot to school, often over significant distances for them. Obviously this may be challenging for a number of reasons, including if the child has impairment which may interfere with their ability to walk a distance on their own, or if they are very young, or alone, all of which may make the child vulnerable. These children may either have to choose a difficult (and expensive) journey to school by the limited public transport options, or may have to be carried the distance by parents or siblings, or they frequently miss out on attending school regularly, if at all.

Where public transport is available, it is more often than not a motorbike taxi, which has better access in harder to reach (often rural) or remote areas, or kombis in towns and some more accessible rural areas. However, even when these options are available for children with disabilities, there were a number of factors preventing their use. At the top of the list of barriers, is the issue of costs, with $72.7 \%$ of head teachers $(\mathrm{N}=66), 70.0 \%$ of teachers ( $\mathrm{N}=180), 76.0 \%$ of caregivers $(\mathrm{N}=179)$ somewhat or totally agreeing that indirect costs, with transportation being a key issue, for schooling are too high.

Compounding these reported barriers is the fact that MWP is a largely rural province, with many remote and hard to reach areas, many of which are surrounded by national parks. Therefore it is perhaps unsurprising that $65.7 \%$ of head teachers $(\mathrm{N}=64)$, and $73.9 \%$ of teachers $(\mathrm{N}=180)$, thought that natural environmental barriers (e.g. animals, rivers, floods, etc.) might be an additional set of barriers preventing children with disabilities from going to school. However, interestingly parents and caregivers were more split about these environmental concerns being a barrier (50.2\% disagree and $49.8 \%$ agree; $\mathrm{N}=179$ ), (Deluca et al, 2014a). Despite the divided opinion regarding environmental barriers, it is clear that parents and teachers both agree that distance, cost and lack of accessible transportation have an impact on the availably, accessibility and type of transport solutions that can be proposed for the area.

\subsection{The Solutions}

It was clear from the survey-based data that distance and (lack of) transport were a factor in exclusion from school for many children. So how did the communities themselves conceptualise these challenges, and what solutions did they propose?

At the initial workshop in 2014, groups from all four of the districts highlighted the rough terrain and lack of paved roads in the localities as challenging. Sandy road surfaces were highlighted as particularly difficult for pushing wheelchairs (if the child was fortunate to actually have one), or cycling-one father took his child to school on the back of his bike. Cycling in these conditions also made bikes liable to punctures and other breakdowns. The roads were also affected by the weather, especially rain. Another effect of the rain was an increase in traffic, so children may be even more delayed on their journey to school. Bad weather was cited as a key factor for many parents deciding to keep their child with a disability home from school on such days, though this is difficult to verify.

There was also some discussion amongst the parents about distances, available transport and context. In one district, participants highlighted that a major access challenge for persons with disabilities to public transport was not just inaccessible vehicles, but the willingness of drivers of kombis or taxis to stop and pick up children and adults with disabilities. One taxi driver explained that he had picked up passengers who use wheelchairs in his taxi (providing the wheelchair could be folded up to fit in boot). Another driver responded by saying they had their own set of challenges when it came to children and adults with disabilities alike. They explained that they have a minimum earning target per day (usually kombis are rented so the drivers need to pay the owner of the vehicle), so any delay can cost money. Therefore having a passenger who is slow to board, or needs to put something on the roof or in the boot of the vehicle, causes a delay and costs them money. This meant they were less likely to stop for them or to pick them up. Moreover, such practices are rarely challenged, particularly from a legal perspective (as discriminatory), so until such time as they are, they are like to continue. Nevertheless, drivers thought taxis might be more flexible and open to negotiation about transporting persons with disabilities, as they have less passengers than the kombis (though of course are more expensive). Everyone agreed that drivers needed to be more aware about persons with disabilities, yet they were rarely included in such discussions.

Workshop participants did discuss some possible solutions to the challenges raised. These ranged from 
tangible inputs such as assistive devices and material goods and resources, including first aid kits for drivers for the (inevitable) accidents to less tangible, such as community awareness raising, and training for drivers. Others called for more accessible public transportwith wide doors, rails, preferential seating; as well as the possibility of free transport and improving the overall condition of the roads. This led to some debate about who was responsible for providing maintenance. As noted above, the GoZ current policy aims to push responsibility for road maintenance and other transport-related factors back onto local communities themselves, rather that the local authorities; in part as a cost saving measure.

There were also some specific issues raised in the four districts: participants from Sanyati raised the issue of road safety as there were no 'robots' (traffic lights) or designated crossing in their community so children were at risk from traffic accidents. But there were other risks identified as well. Parents said they may not accompany their children to or from school if they are busy (with income generating activities, for example), which leaves children unaccompanied and potentially vulnerable to other risks. This particular community is in a former gold mining area but now most of the miners are unemployed. They and their families have little means of income generation or social support, and some participants complained that many of the men spent their days in bars getting drunk, which caused some parents to be anxious that they could pose a risk to their children.

With regard to solutions, this group thought there should be 'less talk and more action'-including the (re)introduction of 'conventional' buses. Others thought that communities themselves could take more responsibility for road maintenance as well as provide input into locations for bus stops and zebra crossings.

In the Mhondoro-Ngezi District group, one visually impaired young man from the community outlined his challenges using public transport, which included trying to identify the correct stop, and having the correct change for the fares. Several members of the group stated that they had not considered some of these issues, and it had made them more aware about them.

Kariba is one of the least accessible districts the area in terms of transport and distance, so perhaps unsurprisingly, the lack of transport options, long distances to anywhere else and wild animals in the vicinity (it borders a national park) were key features of their group discussion. This group specifically mentioned the need for tricycles, as well as the need for pavements, in addition to fencing to keep wild animals at bay. They also mooted dormitories as a school level solution for children with disabilities.

Finally, Hurungwe District participants had an indepth discussion over who should take responsibility for road maintenance in communities. They also brought up the issue of community-based transport co- operatives to support community transport solutions.

In the four post-intervention workshops held almost a year later using the same format, similar themes emerged. Significantly, participants agreed that the availability of transport had increased the likelihood of the children with disabilities attending school (Deluca et al., in press); as well as 'increasing their selfesteem and motivation'. Obviously the LCD inclusive education programme included a range of other factors, such as community sensitisation, school adaptations, and teacher training, so in and of itself just having transport may not be enough-especially if the numbers of children with disabilities attending school continues to increase. For example, some participants argued that depending on the number of journeys needed, time management may actually worsen, especially if the driver is also a teacher at the school. However, overwhelmingly the feedback was positive in that it had increased the likelihood of the children going to-and staying in-school. The extent to which transport alone can be singled out as a factor that ensures children with disabilities can access school is of course debatable; however, the transportation solutions provided did make a significant difference to the parents' daily lives. For example, one participant, highlighting the reduced challenges for parents, said that prior to the introduction of the tricycles some parents had been carrying their children to school on their backs. The availability of transport also freed them up to undertake other (income-generating) activities or household chores.

The majority of children who used the tricycle were children with disabilities; specifically, children included in the LCD IE programme. In most schools, it was the SDC who decided which children got to use the transport, and agreed it with the school administration. In the majority of cases, classroom assistants (another feature of the LCD IE programme in MWP) accompanied the drivers to pick up and drop off the children to and from school. As was common in most schools, the vehicle was also used for additional activities, for example, taking sick children to hospital or to sporting activities. All schools kept their tricycles parked at the school with the keys in safekeeping (usually kept by the school administration).

The new system of transportation therefore created new employment opportunities too. However, some of the drivers were parents of children with disabilities, who may or may not have had previous driving jobs, while others were already employees of the school (in roles such as teachers or caretakers). Very few drivers were given any formal training, either in driving or assisting children with disabilities-which is clearly a gap to be redressed - though some drivers did in practice assist the children to get in and out of the vehicles. There was some debate about what qualifications the drivers needed, including the extent to which 
they needed to know about the children's specific requirements or child protection issues. Some of the drivers had met the children beforehand, and in most schools, the drivers were given a list of children who needed to use the transport, which also may include siblings of children with disabilities. In theory, drivers were voluntary, though in practice, almost all the schools included in the study paid the drivers a small salary (through the SDC). Participants were asked what they thought would be an ideal salary, which they mooted as between US\$250-400 month, depending on location.

Some of the disadvantages of the tricycle highlighted were that they were rather weather dependent as they have no roof or cover. Some schools had made plans to put a tent or cover over the tricycle. A few parents and teachers were worried that the rain may cause the children to be taken home early or brought to school later (though apparently this scenario had not actually happened yet due to the timing of the interventions). Several participants mentioned the poor road conditions, but thought the tricycle could manage them well. Several other participants also raised the issue of safety-as there were no seat belts, first aid kits or fire extinguishers, and drivers were not always aware of safety needs - theirs or the children's. There was also the issue of the children's comfort, and the need to ensure that their health and safety was not compromised on the journey. Participants also wondered to what extend it was a good idea to have teachers as the drivers as on the one hand they may be delayed and be late for lessons, but on the other hand they were more likely to be familiar with the children.

Other challenges highlighted included the vehicle registration process, insurance costs and driver identification (e.g. for security purposed and to check qualifications). Some schools had painted a wheelchair logo (the universal disability sign) onto the trailer to avoid difficulties with the police. Wheelchairs were folded up and attached to the side of the trailer. One driver reported that the police had stopped him because he did not have reflective clothing.

Participants agreed the tricycles were economical to run, with fuel usage varying between 10 litres to 60 litres per week (fuel was around US\$1.5 per litre at time of interview), depending on number of runs they had to do. Drivers at schools with higher numbers of children with disabilities, or at schools that operate a 'split shift', with lessons in the morning and afternoon (mainly in urban areas), often had to do additional school runs to accommodate all the children who needed to use the transport. In most cases, money for fuel was provided by the SDC, from income generating projects. Some children come from as far away as $15 \mathrm{~km}$ from school in more remote areas-these were the children who had not been attending school prior to the project commencing. The tricycles also bought wider benefits; one driver had held a meeting with a village head about road maintenance and through community engagement they were able to ensure the roads were maintained to make them safer for the tricycles to travel on.

Overall the tricycles were seen as relatively economical, suitable for the environment, easily maintained (as parts can be bought locally); as well as having the additional benefit of improving the time management of parents, teachers and pupils. Not all schools chose the tricycle options, and it should also be noted that the total grant available was not enough to cover all the schools in the project,. One of the most remote schools in the area-140km away from the district headquarters-did not have a tricycle as the community thought purchasing fuel would be a problem. In others, there was no tricycle because the SDC chose an alternative option. For example, one school had opted to top up the grant and buy a car (a Toyota Funcargo), rather than a tricycle. Of course, this solution was not without challenges-especially fuel costs, and also raises issues about sustainability and environment. But this community thought it was more effective in rainy weather, and could take children right up to their homes, unlike a kombi van; yet another school in the district wanted to buy a kombi van, using income generating projects to raise fuel costs. Communities therefore had differing views on what they considered to be an 'accessible transport solution'.

In one school without any transport, children with disabilities had to rely on public transport, such as taxis or kombis. This meant they also relied on the driver (and/or classroom assistant) to assist them in and out of the vehicles, as well as tell them where they are going and when to get off. Some parents were worried that the children might end up far from their homes, putting them at risk. They were also worried that though they give the fares to the children, they might spend it on other things, such as sweets or snacks, leaving them with no money to get home. Of particular concern, in one district, as several children lived some distance from the school the SDC said they were considering building residential accommodation for children with disabilities, who, they posited, could be cared for by parents and teachers. However, while this may provide an immediate solution to the problem, it is likely to create far more problems in the long term, as well as perhaps indicate that some teachers (and parents) had not yet fully understood some of the fundamental premises of an inclusive education systemwhich would try to avoid separating children and families at all costs. It would also be additional work for the parents and teachers, without necessarily any additional resources. Interestingly, several of the other workshop attendees disputed this as a 'solution', saying that "if it is a transport problem, then there should be a transport solution". 


\section{Discussion and Conclusion}

What does this information tell us about transport and social exclusion? Does the model piloted in this programme offer a way to support in the inclusion of children with disabilities in the education system? In Zimbabwe, children with disabilities face numerous challenges in accessing the education system. But the education-and transport-systems themselves face numerous challenges in Zimbabwe today, given the current state of the economy and public services (see for example Frye, 2013).

Certainly some of the responses to type of intervention piloted (the tricycle) clearly show that access is understood and experienced differently by groups even in the same context (Church \& Marsden, 2003). The results outlined above demonstrate the challenges are multi-dimensional; relational and dynamic (Lucas, 2012). It was clear from some of the responses that communities were considering much broader issues than just transport for the children with disabilitiesthese ranged from additional life skills training for the children and training for drivers through to road safely and maintenance. Whether this is a result of the programme, or a general increase in awareness is unclear, but either way it is an achievement in itself.

Obviously transport-in this case tricycles-are not the only factor necessary for an inclusive education system, but they have highlighted some crucial gaps in the current approaches, as well as some crucial gaps in the literature around inclusive education. In this paper we have first discussed the impact of transport disadvantage on exclusion (Lucas, 2012) - in this case from the education system. The workshops highlighted the fact that this problem is indeed multi-dimensional: located both within the circumstances of the child who is affected, as well as the processes, institutions and structures in the wider society. Lack of transport may not be the only factor preventing children with disabilities from going to school, but it is a significant one, and may disadvantage those children in relation to the other children in the school.

Access issues range from time constraints for drivers (who receive pay per passenger), which in turn impact on their awareness and willingness to include persons with disabilities amongst their passengers. Conversely, community attitudes toward drivers were often of mistrust. However, as the participants in the workshops have highlighted, drivers were not unwilling to include adults and children with disabilities amongst their passengers, but wanted to ensure that their constraints were also understood. These challenges raise issues around public and private vehicle driver training (especially if they will transport large number of adults and children); as well as legislation. It is clear that there is a need to raise issues of discrimination in accessing transport to the relevant authorities to challenge cur- rent attitudes and practices. It is also important to remember that Zimbabwe did have a relatively good free public transport service for persons with disabilities (though this did not cover all areas) in the past, but due to the political and economic decline, this service is no longer available in most places (Chronicle, 2014).

The workshops also highlighted some of the challenges of coming up with sustainable appropriate, community-based solutions. In the case of the tricycles, it could be argued that these are an economical and effective 'solution'; but further inquiry is needed about what truly 'accessible' is in this context. Is it a solution that is affordable, reliable, regular and safe, or is it a more tailored solution, such as an adapted bus?

There are also broader challenges: the state of the roads, and who should take responsibility for their maintenance-current policy is pushing the onus back on communities themselves. While it seems from some of the respondents cited here that they clearly feel that they could take more responsibility for road maintenance, it also raises questions about the boundaries between civic duty and the role of the state. It may be possible to engage local councils in discussions about improving road conditions if these are linked to concrete examples such as the dangerous road conditions (e.g., pot holes, ruts) for the tricycles. As the tricycles are funded through the SDCs to support access to education, councils may be asked to contribute funds and resources alongside the communities to facilitate an effective compromise.

Then there is the issue of who supplies and maintains the tricycles or other accessible adaptations. This too may be more effective if seen to be a shared responsibility-e.g. with the schools providing transport. But this in turn raises questions of how sustainable funding for the tricycles will be, unless the schools and the communities see the benefits, and that the vehicles are not the sole responsibility of the parents and caregivers of children with disabilities. The evidence above suggests that parents, communities and schools have in some cases been able to come together to ensure that the transport solutions are sustainably and successfully achieved. The question of course, is whether they will be sustained beyond the life of the project.

All of these measures must be seen as dynamic, and against a backdrop of ever changing needs and mobility. As Lucas notes:

"Transport and social exclusion can never survive as a solely transport-focused agenda. The accessibility planning (in its broadest sense) of public transport which is necessary to meet the travel needs of socially excluded people must be highly integrated with socially responsible land use, housing, health, education and welfare policies and programmes." (Lucas, 2012, p. 112) 
It is clear that in Zimbabwe, there are programmes, policies and practices in place, but as yet there is very limited integration between them. Success in reducing transport-related exclusion of children with disabilities from school can therefore only truly be achieved through more coherent, joined up policy making-such as including representatives from the departments of transport, roads and planning in discussions about inclusive education, and education ministry representatives in discussions about urban planning, transportation and mobility; as well as engaging with schools, communities and parents themselves, to better understand their challenges, as well as some of their suggested solutions. In our discussions here, we have tried to demonstrate some of the opportunities there are to do this.

Hopefully what we have also shown here is that policymakers and practitioners working in lower income countries need to be aware that, despite legislation and policies in place, those most marginalised and social excluded are still likely to fall through the gaps, and only by listening to their voices and their suggestions can we begin to develop participatory, community-led solutions that offer a way to try and understand what the challenges are, and develop solutions to overcome-or at least try and avoid-transport-related social exclusion.

\section{Acknowledgments}

This research was made possible with funding from the UK Department for International Development (DFID) Global Poverty Action Fund (GPAF) for the project 'Promoting the Provision of Inclusive Primary Education for Children with Disabilities in Mashonaland West Province, Zimbabwe'. The views expressed here do not necessarily reflect the UK Government's official policies.

The authors would also like to thank $\mathrm{Dr}$ Catherine Holloway (UCL) for her comments on the revised manuscript.

\section{Conflict of Interests}

The authors declare no conflict of interests.

\section{References}

African Development Fund. (2013). National transport sector master plan study: Zimbabwe. African Development Fund. Retrieved from: http://www.afdb.org/ fileadmin/uploads/afdb/Documents/Project-and-Op erations/Zimbabwe_-_National_Transport_Sector_M aster_Plan_Study_-_Appraisal_Report.pdf

Banda-Chalwe, M., Nitz, J., \& de Jonge, D. (2012). Globalising accessibility: Drawing on the experiences of developed countries to enable the participation of disabled people in Zambia. Disability \& Society, 27(7),
917-934. doi: 10.1080/09687599.2012.692024

Bannister, D., \& Hall. P. (1981). Transport and public Policy Planning. London, UK: Continuum International Publishing.

Chideme, M. (2013). Zimbabwe: Govt launches national transport policy. AllAfrica. Retrieved from: http:// allafrica.com/stories/201304170959.html

Chronicle. (2014). Zim transport systems not accessible to disabled people. Chronicle. Retrieved from: http://www.chronicle.co.zw/zim-transport-systemsnot-accessible-to-disabled-people

Church, R., \& Marsden, J. (2003). Measuring accessibility for people with a disability. Geographical Analysis, 1(35), 83-96.

Currie, G., Richardson, T., Smyth, P., Vella-Brodrick, D., Hine, J., Lucas, K. . . . Stanley, J. (2010). Investigating links between transport disadvantage, social exclusion and well-being in Melbourne: Updated results. Research in Transportation Economics, 29, 287-295-

Deluca, M., Tramontano, C., \& Kett, M. (2014a). Inclusive primary education for children with disabilities in Zimbabwe, Mashonaland Province. London: Leonard Cheshire Disability and Inclusive Development Centre.

Deluca, M., Tramontano, C., \& Kett, M. (2014b). Including children with disabilities in primary school: The case of Mashonaland, Zimbabwe (Leonard Cheshire Disability and Inclusive Development Centre working paper series no. 26). London: Leonard Cheshire Disability and Inclusive Development Centre.

Deluca, M., Pinilla-Roncancio, M., \& Kett, M. (2016, in press). Research report: Post intervention survey on knowledge, attitudes and practices (KAP) on disability and inclusive education in Zimbabwe (Mashonaland Province). London: Leonard Cheshire Disability and Inclusive Development Centre.

Frye, A. (2013). Disabled and older persons and sustainable urban mobility. UNHABITAT. Retrieved from: http://unhabitat.org/wp-content/uploads/2013/06/ GRHS.2013.Thematic.Disabled.and_.Older_.Persons. pdf

Groce, N., Kett, M., Lang, R., \& Trani, J. (2011). Disability and poverty: The need for a more nuanced understanding of implications for development policy and practice. Third World Quarterly, 32(8), 1493-1513.

Lucas, K. (2011). Making the connections between transport disadvantage and the social exclusion of low income populations in the Tshwane Region of South Africa. Journal of Transport Geography, 19(6), $1320-1334$.

Lucas, K. (2012). Transport and social exclusion: Where are we now? Transport Policy, 20, 105-113.

Lucas, K., van Wee, B., \& Maat, K. (In press). A method to evaluate equitable accessibility: Combining ethical theories and accessibility-based approaches. Transportation Journal.

Ministry of Health and Child Welfare. (2009). The na- 
tional health strategy for Zimbabwe 2009-2013. Zimbabwe: Harare. Retrieved from: http://apps.who.i nt/medicinedocs/documents/s17996en/s17996en.pdf

Schwanen, T., Lucas, K., Akyelken, N., Solsona, D. C., Carrasco, J. A., \& Neutens, T. (2015). Rethinking the links between social exclusion and transport disadvantage through the lens of social capital. Transportation Research Part A: Policy and Planning, 74, 123-135. doi: 10.1016/j.tra.2015.02.012

Social Exclusion Unit. (2003). Making the connections: Final report on transport and social exclusion. London: Social Exclusion Unit. Retrieved from: http:// www.ilo.org/wcmsp5/groups/public/@ed_emp/@e mp_policy/@invest/documents/publication/wcms_ asist_8210.pdf

Stevens, M., Vitos, M., Altenbuchner, J., Conquest, G., Lewis, J., \& Haklay, M. (2014). Taking participatory citizen science to extremes. Pervasive Computing IEEE, 13(2), 20-29. doi: 10.1109/MPRV.2014.37
United Nations General Assembly. (2007). Convention on the rights of persons with disabilities: Resolution/ adopted by the general assembly, 24 January 2007 (A/RES/61/106). New York, NY: United Nations. Retrieved from http://www.refworld.org/docid/45f97 3632.html

Van Rooy, G., Amadhila, G., Mufune P., Swartz L., Mannan, H., \& MacLachlan, M. (2012). Perceived barriers to accessing health services among people with disabilities in rural northern Namibia. Disability \& Society, 27(6), 761-775. doi: 10.1080/09687599.2012.686 877

Walters, J. (2008). Overview of public transport policy developments in South Africa. Research in Transportation Economics, 22, 98-108.

Whitzman, C., James, K., \& Poweseu, I. (2013). Travelling together: Participatory research methods for disability inclusive road development in Papua New Guinea. Journal of Transport Geography, 26, 65-71.

\section{About the Authors}

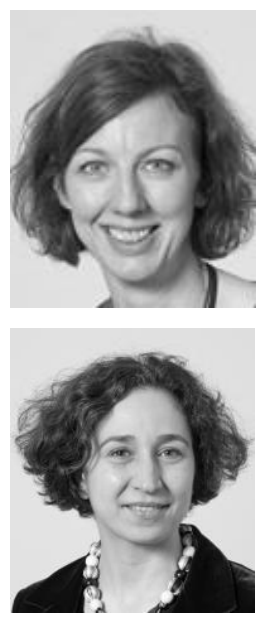

Maria Kett is the Assistant Director of the Leonard Cheshire Disability and Inclusive Development Centre, Department of Epidemiology and Public Health, UCL. An anthropologist by training, Maria has extensive experience of applied policy-focused work in the disability and international development arena, with a particular interest in international health, education and measures to alleviate poverty.

Marcella Deluca is Senior Research Fellow at the Leonard Cheshire Disability and Inclusive Development Centre, Department of Epidemiology and Public Health, UCL. As a social scientist, Marcella has two decades of experience in evidence-based analysis for policy making and guidance. Her area of expertise is in the field of comparative Education policy and practice. Specifically, her work focuses on Inclusive Education, applied research in disability and international development, and measures to alleviate social exclusion. 